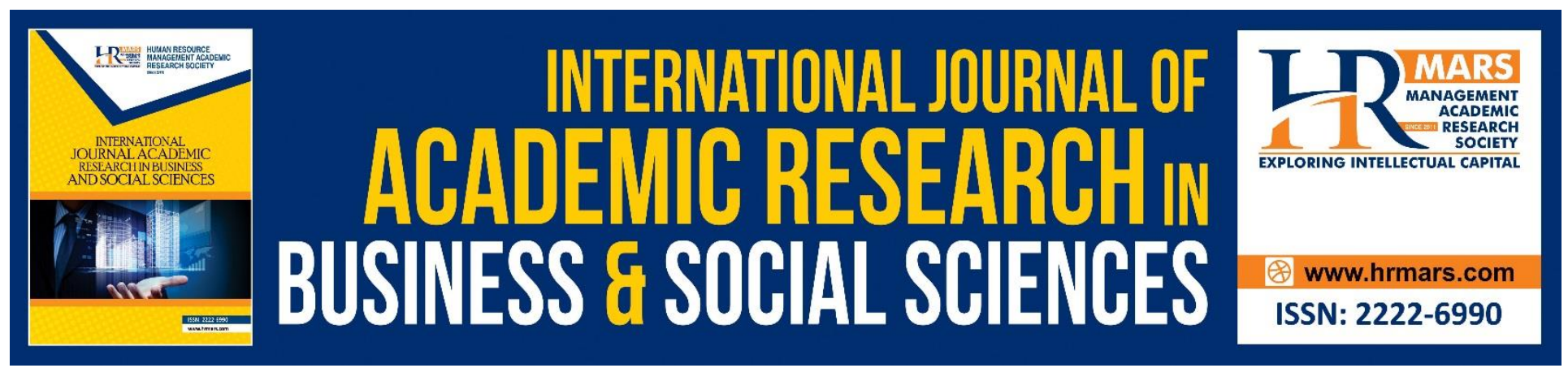

\title{
Computational Thinking: A Strategy for Developing Problem Solving Skills and Higher Order Thinking Skills (HOTS)
}

Nur Lisa Zaharin, Sabariah Sharif, Muralindran Mariappan

To Link this Article: http://dx.doi.org/10.6007/IJARBSS/v8-i10/5297

DOI: $10.6007 /$ IJARBSS/v8-i10/5297

Received: 11 Sept 2018, Revised: 28 Oct 2018, Accepted: 06 Nov 2018

Published Online: 09 Nov 2018

In-Text Citation: (Zaharin, Sharif, \& Mariappan, 2018)

To Cite this Article: Zaharin, N. L., Sharif, S., \& Mariappan, M. (2018). Computational Thinking: A Strategy for Developing Problem Solving Skills and Higher Order Thinking Skills (HOTS). International Journal of Academic Research in Business and Social Sciences, 8(10), 1265-1278.

\section{Copyright: (C) 2018 The Author(s)}

Published by Human Resource Management Academic Research Society (www.hrmars.com)

This article is published under the Creative Commons Attribution (CC BY 4.0) license. Anyone may reproduce, distribute, translate and create derivative works of this article (for both commercial and non-commercial purposes), subject to full attribution to the original publication and authors. The full terms of this license may be seen

at: http://creativecommons.org/licences/by/4.0/legalcode

Vol. 8, No. 10, 2018, Pg. 1265 - 1278

http://hrmars.com/index.php/pages/detail/IJARBSS

JOURNAL HOMEPAGE

Full Terms \& Conditions of access and use can be found at http://hrmars.com/index.php/pages/detail/publication-ethics 


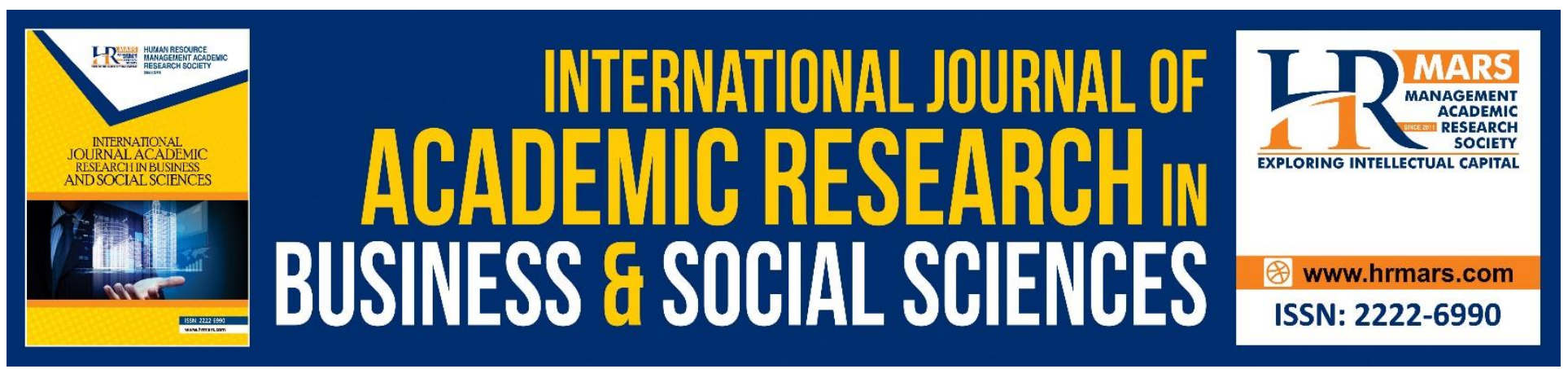

\title{
Computational Thinking: A Strategy for Developing Problem Solving Skills and Higher Order Thinking Skills (HOTS)
}

\author{
Nur Lisa Zaharin ${ }^{1 *}$, Sabariah Sharif ${ }^{2}$, Muralindran Mariappan ${ }^{3}$ \\ ${ }^{1 * 2}$ Education Department, Faculty of Psychology and Education \\ University Malaysia Sabah (UMS), Jalan UMS, 88400, Kota Kinabalu, Sabah, Malaysia \\ ${ }^{3}$ Faculty of Engineering \\ University Malaysia Sabah (UMS), Jalan UMS, 88400, Kota Kinabalu, Sabah, Malaysia
}

\section{Abstract}

The Malaysian Education Blueprint has focused its aspirations to equip students with unparalleled thinking skills. The implementation of Higher Order Thinking Skills (HOTS) has push students to have the ability to solve problems which it is observed to be lacking. Thus, Computational Thinking (CompT) is proposed as a strategy to advocate solving problem skills among students. Other than that, its introduction to the curricula aims in yielding digital creators in this digital era. However, it has its misconceptions and has been perceived similar to Information and Communication Technology (ICT). Thus, this paper aims to change the perception of CompT and present techniques that can be put to use to promote solving problem skills among students. At the same time, it can complement the effort of enhancing HOTS among students

Keywords: Computational Thinking, Higher Order Thinking Skills (HOTS), Problem Solving

\section{Introduction}

Malaysian Education System: Where does it stand now?

The Malaysian National Blueprint 2013-2025 published in 2012 has outlined the necessity of producing students with competent thinking skills. It is necessary for students nowadays to equip themselves with this challenging digital era. Efforts towards it have been observed through the implementation of critical and creative thinking in the Integrated Curriculum for Secondary Schools (ICSS) in 1988 (Salleh and Ayudin, 2010). One of the initiatives done by the Ministry of Education (MOE), is the implementation of Higher Order Thinking Skills (HOTS) into the education syllabus. However, results from The Programme for International Student Assessment (PISA) and Trends in International Mathematics and Science Study (TIMMS) in 2009 indicates the performance of students does not meet the minimum proficiency in Science and Mathematics subjects. Yue-Yi (2016) 
suggested that overemphasis of the examination system, interferences of administration work and frequent change of education policy leads to failure of implementation of HOTS. In fact, HOTS type of question has been introduced in the examination, and its integration into the examination are expected to increase by 2020 .

Furthermore, challenges in promoting HOTS among students has been addressed. Seman et al., (2017) discussed the roles of educators in advocating the government efforts to develop students with HOTS. Teachers find that the integration of HOTS into syllabus has been complex because they need to finish the syllabus and to achieve HOTS elements at the same time. Besides that, teachers also need to recognize students' learning abilities and adjust their way of teaching. Most students are struggling to adapt to inculcate HOTS integrated syllabus learning especially in completing HOTS based tasks and questions in examinations. Other than that, students find it difficult to develop and generate ideas in response to HOTS type of questions (Heong et al., 2010).

\section{What is the solution towards developing HOTS?}

The ability for students' to grasp concepts, to generate knowledge and to solve problems is the mark of their level of competency in thinking skills. Thinking skills can be discussed further through the revised Bloom's Taxonomy model that promotes knowledge and shaping of the skills through cognitive domains of remembering, understanding, applying, analyzing, evaluating and creating. It is divided into two levels of order thinking: Higher-order Thinking Skills (HOTS) and Lower-order thinking skills (LOTS). Each of the levels is connected whereby learners can obtain the highest level of skills, creating if he or she can remember and understand the concepts fully, applied its understanding by analyzing, evaluating and creating.

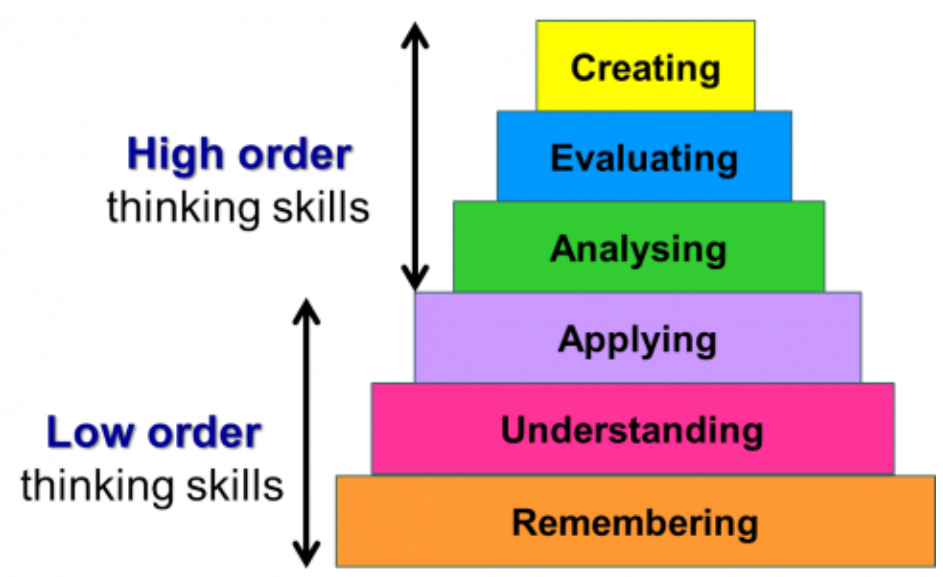

Figure 1: Bloom's Taxonomy Model

The lower part of the Bloom's Taxonomy complements the learning objectives of the higher part of the hierarchy. It presents the level of knowledge and understanding that cannot be applied in generating creative and critical thinking but can be trained through the upper part of the thinking skills that involves the students' skill to create, evaluate and to analyze. Nevertheless, it has been said that Malaysian students are lacking the Higher Order Thinking Skills (HOTS) skills (Dorothy et al., 2016) although efforts in comprehending them have been in progress for over a decade (Nagappan, 2010). 
Developing HOTS among students certainly takes time adding to the fact that Malaysian students are used to being spoon fed (Kassim, 2013) and does not put the effort into solving problems. Thus, how could educators and policymakers respond to this? One of the suggestion is the introduction of 'Computational Thinking' (CompT) into the national curricula (Zainudin, 2016). CompT has caused a spur in the education sector as its introduction has puzzled the academia members. Unfortunately, the concepts of CompT has been misunderstood similar to the concepts of Information and Communications Technology (ICT). It acts as a way to bridge the gap of Science, Technology, Engineering and Mathematics (STEM) skills. Wing (2006) pitched the idea as the skill that students need to grasp to prepare themselves in the $21^{\text {st }}$ century. She discusses that CompT skills are a set of skills that can be applied to everyone, not specifically to be used only by computer scientists.

Generally, Wing (2006) has defined CompT skills as:

"A way of solving problems, designing systems and understanding human behavior by drawing the concepts of computer science."

In another term, CompT skills can be explained as an alternative method in generating solution through mental blocks in the students' mind. She further explained on integrating a CompT set of skills as a part of a discovery and innovation in other fields besides computer science and also crucial to be introduced in the childhood education (Lockwood and Mooney, 2017). Integration of CompT skills is usually linked to science subjects although there are other subjects such as English and literature that CompT skills can be applied to (Weng, 2017; Howell et al., 2011). It is said that the CompT does not have a definite term for the CompT. Thus, Cuny et al., (2010) further elaborated that Computational Thinking as:

"The thought processes involved in formulating problems and their solutions so that the solutions are represented in a form that can be effectively carried out by an information-processing agent."

Barr and Stephenson (2011) have defined the term of CompT that focusses to a specific group that includes the concepts of integrating CompT into the classroom, skills that the students exhibited while executing the project, the role of the teacher in providing the strategies to incorporate CompT in classrooms. However, the integration into the curricula is said to be difficult (Ling et al., 2016) although the concepts have been used unknowingly in their practice. CompT is associated as an approach to develop problem-solving skills (Zainudin, 2016) and has been suggested to be added in the ' $C$ ' list of the $21^{\text {st }}$ century: Critical Thinking, Creativity, Collaboration and Communication skills that are identified as the necessary skills in the school curricula (Grover, 2018).

Moreover, the impact of industrial revolution 4.0 (IR 4.0) has demanded the need for CompT skills to be embedded in the syllabus. IR 4.0 is the waves of cyber-physical software that is the result of the foundation of the third Industrial Revolution. IR 3.0 applied the use of electronics and information technology for product automation. Meanwhile, IR 4.0 is the combination of the information technology and fusion of other technologies such as Augmented Reality (AR), robotics, 3-D printing, internet of things and autonomous vehicles to name a few (Bahrin et al., 2016) and digital, physical and biological systems. Due to this, it certainly has changed the way humans live, eat and even think. In order to meet the movement, the academic society started to integrate technology into the education field. Integrating educational technology into the process of teaching and learning has changed the landscape of a traditional classroom. Ranai (2018) reported on the revamp of the Malaysian Higher Education System in embracing the Industry 4.0. The revamp is done in order to 
keep up Malaysian students in the competitive workforce industry due to the IR 4.0. It emphasizes on the change in teaching and learning process which should be digitalized. Virtual based learning that combines the latest technology into the syllabus should be the focus of the latest approach of the Higher Education System in Malaysia. Other than that, assessment without examination should be the core element to look into in the Education IR 4.0 as the demands of the workforce requires more than just examination results (Kandasivam, 2017).

\section{ICT and CompT Activities}

The integration of technology into syllabus is certainly not a new thing as ICT has embedded its application in the early of 2000s (Ismail et al., 2007; Neo and Neo, 2004). Its use has been applied in the education field where educators are pushed to replace their conservative teaching methods into the use of technology tools and facilities. Simin and Sani (2015) discussed that integration of technology certainly benefited educators by providing learning aid and support to promote effective teaching and learning in classrooms. Continuous, meaningful learning can be constructed through means of educational videos, stimulations, mind-mapping and guided discovery. The difference between ICT and CompT lies within the definition and concepts. ICT can be defined as a medium and tool for teaching and learning (Jager and Lokman, 1999) in order to promote communication, storage and managing information between students and teachers.

Meanwhile, CompT is defined as a strategy to formulate problem based on the computer science concepts of abstraction, decomposition, algorithms, logic, patterns, and evaluation (Shute et al., 2017). Thus, this is where CompT and computer science subjects comes in different. CompT is not a tool or medium. Instead, it is treated as a way of thinking as computers think in providing solutions to-a specific tasks. In fact, its integration can be promoted into 'plugged' or 'unplugged' activities that can be executed in classrooms (Tsarava et al., 2017).

One of the 'plugged' activities that can be done is through the use of robotic, LED and coding agent stimulation, Logo-based technology with the application of CompT elements into it. Learners will be engaged with the idea of creating things, and by allowing to connect deeper into the CompT elements, students are encouraged to solve the problem of the challenges or tasks given. From the knowledge gained, they can apply to their process of innovation and creation. Wilkerson and Fenwick (2016), for example, applied CompT concepts of pattern in their activities in investigating of air quality in the city involving a group of high schools students. The students are required to identify the trends and the factors that might have direct or indirect of the air quality. This study emphasizes the use of mathematical tools and GPS technology that allows the students to collect data quantitatively. In a way, CompT skills are exhibited through data analysis obtained by identifying the trends, contributing factors and predicting the level of air quality after. Another example that can look into the literature of Dukeman et al., (2013) that applied the CompT concepts into the everyday routine of facing traffic routine to enhance students' ability to solve problems with the C3STEM instrument. The collaboration of students are encouraged, and this project-based learning promotes suggestion in improving traffic in their local community.

As such, concepts of CompT does not have to include the use of instruments of tools or in other words 'unplugged,' it can be integrated into lessons by interactive games such as Hopscotch or Scratch. It can also be put into classrooms by explaining scientific terms that are considered hard to be digested 
by students. For example, by decomposing the term 'Photosynthesis' into 'Photo' which means light and 'Synthesis' means to produce. Students can relate this two terms and allows the abstraction of the term in their mind so that a deeper understanding and connection on this term can be done. Bers (2017) added that another alternative method to introduce coding to children is through games that promotes-social interaction between them such as 'Simon Says.' Other 'unplugged' activity such as magic tricks activity can also promote the CompT skills among learners. Since magic tricks activity requires a series of steps that must be followed precisely and accordingly to the right order so that the magic trick can be performed well. Its similarities lies-within the concepts of the algorithm in CompT Other than that; board games can also stimulate the CompT elements. Apostolellis et al., (2014) suggested RabBit EscApe as a tool to advocate solving problem skills for young children collaboratively. Either way, educators need to understand the foundation that makes up the CompT to allow them to implement them in their classroom creatively.

Since the Malaysian Education of Ministry has implemented HOTS in the syllabus, CompT can be a strategy for educators to develop a 'solving problem' mind through the six concepts of CompT. However, educators find it hard to implement the CompT in their teaching. Ribero et al., (2013) highlights the challenges of introducing CompT in Brazil schools requires the need to change the curricula, training of educators and government policies. The misconception of CompT that are perceived as an IT subject instead (Corradini et al., 2017; Ling et al., 2017) indicated a weak understanding of CompT among them.

Thus, this paper hopes to present ideas in implementing CompT into the syllabus in order to give a foundation of CompT and ways to integrate the elements of CompT into the syllabus. In a way, this paper provides information and can change the perception and misconceptions towards CompT and its element that can develop solving problem skills among students.

\section{Computational Thinking: Techniques and its Examples}

Since the CompT involves with the Seymond Paperts' Constructionism theory (Bers, 2017), it mainly revolves around the idea of:

a) Learning by designing meaningful projects to share in the community

b) Using concrete objects to build and explore the world

c) Identifying powerful ideas from focus study

d) Engage in self-reflection as part of the learning process

Thus, any works in implementing CompT into the syllabus must have the approach to the theory itself. It has been reported that techniques in promoting CompT includes tinkering (Bers, 2014), creating, debugging, preserving and collaborating ("Computational Thinking - Barefoot Computing," 2014). CompT skills executed need to be at its maximum potential so that the benefits of CompT skills among students can be gained.

\section{Techniques of applying CompT skills in the curricula}

The following section focuses on literatures-that advocates techniques on CompT that educators can put into use in their practices. These literatures may have applied the pedagogical approach in the constructivism theory mentioned by Bers (2017). Either way, they may have promoted CompT and 
INTERNATIONAL JOURNAL OF ACADEMIC RESEARCH IN BUSINESS AND SOCIAL SCIENCES

Vol. 8, No. 10, Oct. 2018, E-ISSN: $2222-6990$ @ 2018 HRMARS

problem-solving skills through the 'plugged in' and 'unplugged' activity or projects that they have handled:

(i) Tinkering

Tinkering can be defined as the act of trying out. Common among learners that would like to explore further on new concepts or if they have uncertainties in their understanding towards a concept. It is a an instinct to tinker in order to gain full understanding and acceptance in a concept. The act of trying out new concepts or ideas also benefit students to have an independent learning process. By implementing CompT concept into classrooms, student is required to tinker in order to meet the objective of a syllabus. In other words, tinkering allows students to have more freedom in trying out new ideas and implement a carefree creative environment for them to explore deeper.

In the early years of learning, tinkering is a common attitude among students. It also involves developing questions in themselves as students in this phase are driven to have an inquiry nature in themselves. This inquiry nature within them leads them to explore science informally (Wight et al., 2015). Bers et al., (2014), for example, explored the application of educational robotics programmes namely Tangiblek Robotics Programme as a tool to engage kindergarten children in instilling CompT skills among them. The first lesson of the programme involves the introduction of robotics through the building of non-robotic vehicles of toys to transport people. It is then continued with lessons of sharing ideas, designing and building their robots. This level requires the abstraction element of CompT that allows students to explore their imagination in building their robots creatively. It is then followed by the phase of sequence programming that highlights the algorithm and logic elements of CompT. Students are allowed to choose relevant instructions and arrange them accordingly for the robots to move.

Other than that, tinkering is also promoted through the 'Lattice Land' programme. It acts as a mathematical tool in understanding 'Geometry' chapters in Mathematics subject. It is a program that comprises spreadsheets of dots that allows users to construct any geometry shapes. These allows students to explore geometry concepts that includes that calculation of areas and perimeter using tools provided in the programme (Pei et al., 2018). This research supported both of constructionism and constructivism theory. This theory promoted the learning process when a child is actively gaining knowledge through experiences and 'Do-it-Yourself' activity. Both of the literatures applied to the constructionism theory mentioned above, which proves the project designed have contributed elements to the theory mentioned by Bers (2017). Inspired by these, Kotsopoulus et al., (2017) proposed a pedagogical framework of CompT that is developed from this two connected theories. The researcher suggested a framework of CompT that includes pedagogical experiences from unplugged, tinkering, making and remixing activities. This framework can benefit teachers especially regarding ideas that can connect CompT elements into the classroom. Meanwhile, Bers (2017) proposed a Positive Technological Development (PTD) framework that helps teachers to describe and connect positive behaviors with the technology use.

In a way, tinkering allows students to explore their creativity and independence in sharing and designing their ideas to others. Unknowingly, the elements of CompT can be instilled during the process. As such, the ability to analyze tasks given is one of the HOTS components that is lacking 
among Malaysian students; thus, through this CompT strategy of tinkering, students can step-by-step develop the mental tools of solving the problem.

(ii) Creating

Meanwhile, 'creating' is considered the skills of planning, making and evaluating procedures in a project. In creating, the skills are unknowingly being instilled among students while executing the project planned. Creating is commonly linked to game making and design. From the techniques of creating, creative thinking can be sharpened and enhanced CompT development (Shell et al., 2017) Examples like de Paula et al., (2018) applied 'Playing Beowulf' poem into games design. The game created is done by the software of 'Mission Maker' that allows students to create a 3D games through the creation of rooms, props, and environment from the poem. In a way, implementing CompT through this technique can connect the element of arts and game designs. These unconventional combination leads to a different method for students to understand poems and literature that are deemed as boring for students (Khatib, 2011). It motivates them to continuereading for them and at the same time, able to design games that have the same 'vibe' similar to the poem they read. From this, students can learn to programme at the same time (Kazimoglu et al., 2012).

Apart from that, CompT skills are stimulated through a series of programming activities that highlights the creativity element Romero et al., (2017). 'Scratch' is one of the tools that promotes CompT and has been associated with the development of CompT skills among students (Marcelino et al., 2018). The complexity of using 'Scratch' programmes allows the learner to create and write step by step algorithms in code programming. With Scratch, CompT can be promoted through a series of learning with either educational robotics or creative programming codes. These are supported by Romero (2016) who stated that there are five levels of learning to code through passive exposure programming lectures/resources, step-by-step procedural of programming, content creation individually, collaborative content creation and participatory co-creation of programming.

The creativity technique is also the research focus of Tsarava et al., (2017) who outlined lessons to train students CompT by gamification method. However, their method combines both of 'plugged' and 'unplugged' elements. The early phase of the lesson requires students to explore elements of CompT through 'unplugged' games of a treasure hunter. The activity requires students to move from one point to another by a sequence of commands written on cards. The next lesson outlined then integrate CompT concepts of controls and coding into the games of mazes. The upper stage of activity includes 'plugged' activities such as developing codes through Scratch or invention of Apps through Applnventor. The literature highlights the necessity of creating new inventions instead of being a normal digital user. It is aligned to Singh (2016) who discussed that the CompT skills could be the 'push' in transforming a generation of digital creators. For that, this 'creating' approach moves the initiatives in formulating solutions among students. In a way, students will be motivated to finish the tasks given as they have no set of boundaries or rules that they need to abide with.

(iii) Debugging

In continuation of the techniques in CompT, debugging is part of the ways of achieving CompT skills. It is a process of analyzing step by step algorithm and fixing any error present. Any error requires evaluation and formulation of the solution, thus, enhancing the solving problem minds among students. It is usual for programmers to make a mistake while writing programming codes. Hailpern and Santhanam (2002) discussed that the idea of debugging is to identify and fix codes that are 
INTERNATIONAL JOURNAL OF ACADEMIC RESEARCH IN BUSINESS AND SOCIAL SCIENCES

Vol. 8, No. 10, Oct. 2018, E-ISSN: 222 2-6990 @ 2018 HRMARS

responsible for errors. Usually occurs in developing software and the process can be explained through steps of:

(1) Coding process: A process when the programmer translates the design into code that can be used. These are the process that requires programmers to identify where the 'bug' is located and formulate a solution to the error. Programmers usually will test their codes in this phase before going to the next stage of programming.

(2) Deployment: Software programmed undergoes the 'real' operational conditions in which any unresolved bug will be exposed at this phase and requires a large scale problem determination that needs to be fixed.

Since CompT is associated with building the mental blocks of problem-solving, debugging is part of the solution formulation especially in a programming language. Not only that, it is demonstrated that ScratchEd Team (2017) has provided strategies in the debugging process to guide students or educators if they are facing challenges in writing codes or blocks in the programme. They even provided resources for debugging through websites and forums.

1) http://scratched.gse.harvard.edu/sites/default/files/debug it.pdf

2) http://scratched.gse.harvard.edu/stories/see-inside-classroom-emily-roach

3) http://scratched.gse.harvard.edu/discussions/discussion-about-scratch/sub-discussion

These links are provided in the internet easily as if the ScratchEd Team expected the mistakes to appear while writing codes and blocks in the Scratch programme. CompT skills through debugging have certainly had the ability to shape up a students' personality. This technique will be further be improved through the next technique discussed, that is preserving and collaborating.

(iv) Preserving

Throughout the process, preserving is one of the best ways of developing CompT among students. CompT programming tools allows students to explore new skills of coding which students tend to make mistakes along the way. Students need to preserve the learning process in order to achieve the objective of the project or activity designed. Dweck (2014) emphasizes that individuals need to have the perseverance factor and hard work to get the outcome of the effort. Results demonstrated connections in the brain can be formed as they encounter tasks that challenge their mind. Confidence will be obtained through the 'try and error' phase. Due to this, collaboration among peers is necessary through activities such as brainstorming so that the problem-solving process and thinking can occur. Chowdhury (2015) reported that the students exhibited a positive attitude when working in groups. Students' anxiety can be reduced, and effective learning can take into place.

(v) Collaborating

Meanwhile, the idea of linking collaborative and CompT can be seen through the study of Worrell et al., (2015) which they introduced a programme that promoted collaboration through designing games and simulations which can be used in a classroom setting. Farris and Sengupta (2014) combined the idea of CompT into Physics subjects through modeling activity. Students are observed to have more engagement in the idea of collaborative based activity. Teamwork and learning can work hand in hand to achieve meaningful learning, thus, executing the constructionism theory mentioned by Papert (1980). Some of the programming websites are lacking the CompT elements in it, thus, 'Make World'are created in order to fill the gaps in it. Make World; an online programming 
website allows sharing and assessing of the programming websites combining CompT and Science, Technology, Engineering and Mathematics (STEM) subjects with others worldwide.

It can be seen that projects involving coding and robotics enhance the sense of collaborative, persistence and communication skills among students. (Berdik, 2015; Basogain et al., 2008). Besides that, the establishment of extra curricula clubs by universities that promotes CompT skills through gamification and app development is also observed through the works of Guenaga et al., (2017). Thus, it presented the flexibility of CompT activities that can be introduced in after-school programs. Activities or projects discussed in this section presented techniques in achieving CompT skills among students. However, challenges in promoting CompT can be addressed through the readiness and perceptiveness of educators towards it (Ling et al., 2017). Other than that, intrinsic challenges of CompT such as teachers' knowledge and understanding, teachers; attitude and values, and their approaches are discussed as one of the problems that most teachers faced (Sentence and Csizmadia, 2017).

\section{Conclusion}

Literature discussed in the previous section discussed the possibilities of introducing Computational Thinking through 'plugged' or 'unplugged' activities that can be used as examples for educators to be used in their daily practice. However, how can CompT and HOTS be linked? The answer lies in the 'problem solving' element of CompT. The concepts of CompT highlights the steps required in solving the problem. Since HOTS have the element of analyzing, creating and evaluating, CompT activities are observed to complement the effort to promote HOTS through solving problems among students. It is certainly aligned with Papert's (1980) approach of constructionism theory. On top of that, CompT requires the concepts of evaluation and perseverance which can be the added factor in shaping the creators and innovators of the future. In terms of the Malaysian educational scene, Malaysian students have presented vast potential. However, it is not fully explored due to constraints of time, misconceptions and over-emphasis of examination. Although efforts of instilling CompT as an approach to advocate problem solving and HOTS among students, more work still need to be done.

\section{Corresponding Author}

Nur Lisa Zaharin ${ }^{1^{*}}$

Education Department,

Faculty of Psychology and Education, Universiti Malaysia Sabah (UMS), Jalan UMS, 88400, Kota Kinabalu, Sabah

E-mail: lisazay1@gmail.com

\section{References}

Apostolellis, P., Stewart, M., Frisina, C., \& Kafura, D. (2014, June). RaBit EscAPE: a board game for computational thinking. In Proceedings of the 2014 conference on Interaction design and children (pp. 349-352). ACM.

Barr, V., \& Stephenson, C. (2011). Bringing computational thinking to K-12: what is Involved and what is the role of the computer science education community?. Acm Inroads, 2(1), 48-54. 
INTERNATIONAL JOURNAL OF ACADEMIC RESEARCH IN BUSINESS AND SOCIAL SCIENCES Vol. 8, No. 10, Oct. 2018, E-ISSN: 222 2-6990 @ 2018 HRMARS

Basogain, X., Olabe, M. Á., Olabe, J. C., \& Rico, M. J. (2017). Computational Thinking in pre-university Blended Learning classrooms. Computers in Human Behavior, 30, 1 e8

Bahrin, M. A. K., Othman, M. F., Azli, N. N., \& Talib, M. F. (2016). Industry 4.0: A review on industrial automation and robotic. Jurnal Teknologi, 78(6-13), 137-143.

Berdik, C. (2015). Can Coding Make the Classroom Better?. Retrieved from http://www.slate.com/articles/technology/future tense/2015/11/computational thinking teaches kids coding_collaboration_and_problem_solving.html

Bers, M. U. (2017). Coding as a playground: Programming and computational thinking in the early childhood classroom. Routledge.

Bers, M. U., Flannery, L., Kazakoff, E. R., \& Sullivan, A. (2014). Computational thinking and tinkering: Exploration of an early childhood robotics curriculum. Computers \& Education, 72, 145-157.

Chowdhury, B. (2015, July). Understanding Collaborative Computational Thinking. In Proceedings of the eleventh annual International Conference on International Computing Education Research (pp. 251-252). ACM.

Computational Thinking - Barefoot Computing. (2014).Retrieved from https://barefootcas.org.uk/barefoot-primary-comput ing-resources/concepts/computationalthinking/.

Corradini, I., Lodi, M., \& Nardelli, E. (2017, August). Conceptions and misconceptions about computational thinking among Italian primary school teachers. In Proceedings of the 2017 ACM Conference on International Computing Education Research (pp. 136-144). ACM.

Cortez, M. B. (2016). Teaching Computational Thinking Is the First Step to Bridging STEM Skills Gap. Retrieved from https://edtechmagazine.com/k12/article/2016/11/tea ching-computationalthinking-first-step-bridging-s tem-skills-gap.

Cuny, J., Snyder, L., \& Wing, J. M. (2010). Demystifying computational thinking for non-computer scientists. Unpublished manuscript in progress, referenced in http://www. cs. cmu. edu/ CompThink/resources/TheLinkWing. pdf.

De Paula, B. H., Burn, A., Noss, R., \& Valente, J. A. (2018). Playing Beowulf: Bridging computational thinking, arts and literature through game-making. International journal of child-computer interaction, 16, 39-46.

Dukeman, A., Caglar, F., Shekhar, S., Kinnebrew, J., Biswas, G., Fisher, D., \& Gokhale, A. (2013). Teaching computational thinking skills in c3stem with traffic simulation. In Human-Computer interaction and knowledge discovery in complex, unstructured, big data (pp. 350-357). Springer, Berlin, Heidelberg.

Dorothy, D., Alias, N., \& Siraj, S. (2016). Problem solving strategies of Malaysian secondary school teachers.

Dweck, C. S., Walton, G. M., \& Cohen, G. L. (2014). Academic Tenacity: Mindsets and Skills that Promote Long-Term Learning. Bill \& Melinda Gates Foundation.

Grover., S. (2018). The 5th ' $C$ ' of 21st Century Skills? Try Computational Thinking (Not Coding) EdSurge News.Retrieved from https://www.edsurge.com/news/2018-02-25-the-5th-c- of-21stcentury-skills-try-computational-thinking- not-coding.

Farris, A. V., \& Sengupta, P. (2014). Perspectival computational thinking for learning physics: A case study of collaborative agent-based modeling. arXiv preprint arXiv:1403.3790. 
INTERNATIONAL JOURNAL OF ACADEMIC RESEARCH IN BUSINESS AND SOCIAL SCIENCES Vol. 8, No. 10, Oct. 2018, E-ISSN: 222 2-6990 @ 2018 HRMARS

Ismail, Z., Zakaria, H. M., \& Aziz, Z. (2007). The implementation of Internet integration in the teaching of History subject in Putrajaya. In Proceedings of the 1st International Malaysian Educational Technology Convention (pp. 94-100).

Kandasivam., A. (2016). Collaboration key to relevant education in Industry 4.0. Retrieved from https://www.digitalnewsasia.com/digital-economy/collaboration-key-relevant-education-industry40.

Kazimoglu, C., Kiernan, M., Bacon, L., \& MacKinnon, L. (2012). Learning programming at the computational thinking level via digital game-play. Procedia Computer Science, 9, 522-531.

Hailpern, B., \& Santhanam, P. (2002). Software debugging, testing, and verification. IBM Systems Journal, 41(1), 4-12.

Heong, Y. M., Yunosb, J. B. M., binti Osmanc, N., binti Ibrahim, S., \& Sulongd, T. T. K. (2010). The perception of student on mastering the level of higher order thinking skills in technical education subjects.

Howell, L., Jamba, L., Kimball, A. S., \& Sanchez-Ruiz, A. (2011, March). Computational thinking: modeling applied to the teaching and learning of English. In Proceedings of the 49th Annual Southeast Regional Conference (pp. 48-53). ACM.

Guenaga, M., Menchaca, I., Garaizar, P., \& Eguíluz, A. (2017, October). Trastea. club, an initiative to develop computational thinking among young students. In Proceedings of the 5th International Conference on Technological Ecosystems for Enhancing Multiculturality (p. 10). ACM.

Kasim., Z. (2013). Rethinking our education system - Education | The Star Online. Retrieved July 19, 2018 from https://www.thestar.com.my/news/education/2013/06/ 30/rethinking-our-educationsystem/

Khatib, M. (2011). A new approach to teaching English poetry to EFL students. Journal of language teaching and research, 2(1), 164.

Kotsopoulos, D., Floyd, L., Khan, S., Namukasa, I. K., Somanath, S., Weber, J., \& Yiu, C. (2017). A pedagogical framework for computational thinking. Digital Experiences in Mathematics Education, 3(2), 154-171.

Ling, U. L., Saibin, T. C., Labadin, J., \& Aziz, N. A. (2017). Preliminary Investigation: Teachers' Perception on Computational Thinking Concepts. Journal of Telecommunication, Electronic and Computer Engineering (JTEC), 9(2-9), 23-29.

Lockwood, J., \& Mooney, A. (2017). Computational thinking in education: Where does it fit. $A$ systematic literary review. arXiv preprint.

Malaysia ranks 52 out of 65 countries in international assessment programme - Nation | The Star Online. (2013).Retrieved from https://www.thestar.com.my/news/nation/2013/12/05/ studentsscore-below-global-average-malaysia-ranks -52-out-of-65-countries-in-international-assessmen /. Marcelino, M. J., Pessoa, T., Vieira, C., Salvador, T., \& Mendes, A. J. (2018). Learning Computational Thinking and scratch at distance. Computers in Human Behavior, 80, 470-477.

Nagappan, R. (2010). Teaching thinking skills at institutions of higher learning: Lessons learned. Pertanika Journal of Social Science \& Humanities, 18, 1-14.

Neo, T. K., \& Neo, M. (2004). Integrating Multimedia into the Malaysian Classroom: Engaging Students in Interactive Learning. Turkish Online Journal of Educational Technology-TOJET, 3(3), 3137. 
INTERNATIONAL JOURNAL OF ACADEMIC RESEARCH IN BUSINESS AND SOCIAL SCIENCES

Vol. 8, No. 10, Oct. 2018, E-ISSN: 222 2-6990 @ 2018 HRMARS

OECD (2010), PISA 2009 Results: Executive Summary

Papert, S. (1980). Mindstorms: Children, computers, and powerful ideas. Basic Books, Inc..

Pei, C., Weintrop, D., \& Wilensky, U. (2018). Cultivating Computational Thinking Practices and Mathematical Habits of Mind in Lattice Land. Mathematical Thinking and Learning, 20(1), 75-89.

Ranai., M. (2018). 2018 MANDATE: Embracing Industry 4.0 | Higher Education Today. Retrieved from http://news.mohe.gov.my/2018/01/27/2018-mandate-em bracing-industry-4-0/.

Ribeiro, L., Nunes, D. J., Da Cruz, M. K., \& Matos, E. D. S. (2013, October). Computational thinking: Possibilities and challenges. In Theoretical Computer Science (WEIT), 2013 2nd Workshop-School on (pp. 22-25). IEEE.

Romero, M., Davidson, A. L., Cucinelli, G., Ouellet, H., \& Arthur, K. (2016). Learning to code: from procedural puzzle-based games to creative programming. Revista del Congrés Internacional de Docència Universitària i Innovació (CIDUI), (3).

Romero, M., Lepage, A., \& Lille, B. (2017). Computational thinking development through creative programming in higher education. International Journal of Educational Technology in Higher Education, 14(1), 42

Salleh, M. J., \& Ayudin, A. R. (2010). Innovations of History Education in the High Schools, ICSS, Malaysia. HISTORIA-International Journal of History Education, 11(2), 73-88.

ScratchEd Team. (2017). Debugging in Scratch: Resources and Strategies | ScratchEd. Retrieved from http://scratched.gse.harvard.edu/resources/debuggi ng-scratch-resources-and-strategies.

Seman, S. C., Yusoff, W. M. W., \& Embong, R. (2017). Teachers challenges in teaching and learning for higher order thinking skills (HOTS) in primary school. International Journal of Asian Social Science, 7(7), 534-545.

Sentance, S., \& Csizmadia, A. (2017). Computing in the curriculum: Challenges and strategies from a teacher's perspective. Education and Information Technologies, 22(2), 469-495.

Shell, D. F., Hazley, M. P., Soh, L. K., Miller, L. D., Chiriacescu, V., \& Ingraham, E. (2014, October). Improving learning of computational thinking using computational creativity exercises in a college CSI computer science course for engineers. In Frontiers in Education Conference (FIE), 2014 IEEE (pp. 17). IEEE.

Simin, G., \& Sani, I. M. Effectiveness of ICT Integration in Malaysian Schools: A Quantitative Analysis. Singh.., K. (2016). Computational thinking comes to the fore in Malaysian schools. Retrieved from https://www.digitalnewsasia.com/digital-economy/computational-thinking-come-fore-malaysianschools.

Tsarava, K., Moeller, K., Pinkwart, N., Butz, M., Trautwein, U., \& Ninaus, M. (2017, October). Training computational thinking: Game-based unplugged and plugged-in activities in primary school. In European Conference on Games Based Learning (pp. 687-695). Academic Conferences International Limited.

Shute, V. J., Sun, C., \& Asbell-Clarke, J. (2017). Demystifying computational thinking. Educational Research Review.

Singh.K. (2016). Computational thinking comes to the fore in Malaysian schools. Retrieved from https://www.digitalnewsasia.com/digital-economy/co mputational-thinking-come-fore-malaysianschools 
INTERNATIONAL JOURNAL OF ACADEMIC RESEARCH IN BUSINESS AND SOCIAL SCIENCES

Vol. 8, No. 10, Oct. 2018, E-ISSN: $2222-6990$ ㄷ 2018 HRMARS

Weng, X., \& Wong, G. K. (2017, December). Integrating computational thinking into english dialogue learning through graphical programming tool. In Teaching, Assessment, and Learning for Engineering (TALE), 2017 IEEE 6th International Conference on (pp. 320-325). IEEE.

Wilkerson, M. H., \& Fenwick, M. (2017). Using mathematics and computational thinking. Helping students make sense of the world using next generation science and engineering practices, 181-204. Wing, J. M. (2006). Computational thinking. Communications of the ACM, 49(3), 33-35.

Worrell, B., Brand, C., \& Repenning, A. (2015, October). Collaboration and Computational Thinking: A classroom structure. In Visual Languages and Human-Centric Computing (VL/HCC), 2015 IEEE Symposium on (pp. 183-187). IEEE.

Yue-Yi, H. (2016). From drills to skills? Cultivating critical thinking, creativity, communication, and collaboration through Malaysian schools.

Zainidin., F. (2016). Enhancing Students' Higher Order Thinking Skills (HOTS) via Computati... Retrieved from https://www.slideshare.net/Fadzliaton/enhancing-st udents-higherorder-thinking-skills-hots-via-compu tational-thinking-and-digital-literacy. 